\title{
Intrapulmonary Activation of the Angiotensin-Converting Enzyme Type 2/Angiotensin 1-7/G-Protein-Coupled Mas Receptor Axis Attenuates Pulmonary Hypertension in Ren-2 Transgenic Rats Exposed to Chronic Hypoxia
}

\author{
V. HAMPL ${ }^{1}$, J. HERGET ${ }^{1}$, J. BÍBOVÁ ${ }^{1}$, A. BAŇASOVÁ ${ }^{2}$, Z. HUSKOVÁ $^{3}$,

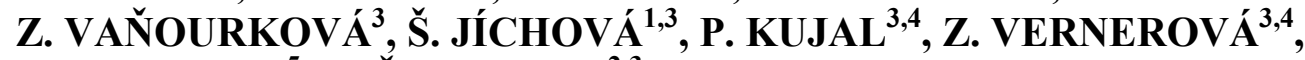 \\ J. SADOWSKI ${ }^{5}$, L. ČERVENKA ${ }^{2,3}$
}

${ }^{1}$ Department of Physiology, Second Faculty of Medicine, Charles University, Prague, Czech Republic, ${ }^{2}$ Department of Pathophysiology, Second Faculty of Medicine, Charles University, Prague, Czech Republic, ${ }^{3}$ Center for Experimental Medicine, Institute for Clinical and Experimental Medicine, Prague, Czech Republic, ${ }^{4}$ Department of Pathology, Third Faculty of Medicine, Charles University, Prague, Czech Republic, ${ }^{5}$ Department of Renal and Body Fluid Physiology, M. Mossakowski Medical Research Centre, Polish Academy of Science, Warsaw, Poland

Received July 3, 2014

Accepted July 21, 2014

On-line September 5, 2014

\section{Summary}

The present study was performed to evaluate the role of intrapulmonary activity of the two axes of the renin-angiotensin system (RAS): vasoconstrictor angiotensin-converting enzyme (ACE)/angiotensin II (ANG II)/ANG II type 1 receptor (AT 1 ) axis, and vasodilator ACE type 2 (ACE2)/angiotensin 1-7 (ANG 1-7)/ Mas receptor axis, in the development of hypoxic pulmonary hypertension in Ren-2 transgenic rats (TGR). Transgene-negative Hannover Sprague-Dawley (HanSD) rats served as controls. Both TGR and HanSD rats responded to two weeks' exposure to hypoxia with a significant increase in mean pulmonary arterial pressure (MPAP), however, the increase was much less pronounced in the former. The attenuation of hypoxic pulmonary hypertension in TGR as compared to HanSD rats was associated with inhibition of ACE gene expression and activity, inhibition of $\mathrm{AT}_{1}$ receptor gene expression and suppression of ANG II levels in lung tissue. Simultaneously, there was an increase in lung ACE2 gene expression and activity and, in particular, ANG 1-7 concentrations and Mas receptor gene expression. We propose that a combination of suppression of $A C E / A N G$ II/AT 1 receptor axis and activation of ACE2/ANG 1-7/Mas receptor axis of the RAS in the lung tissue is the main mechanism explaining attenuation of hypoxic pulmonary hypertension in TGR as compared with HanSD rats.

\section{Key words}

Hypoxic pulmonary hypertension • Renin-angiotensin system

\section{Corresponding author}

L. Červenka, Department of Pathophysiology, Second Faculty of Medicine, Charles University, Prague, Czech Republic. E-mail: luce@medicon.cz

\section{Introduction}

Even though hypoxic pulmonary hypertension is not per se a life-threatening consequence of high altitudeinduced alveolar hypoxia, the development of right ventricle failure observed in considerable subgroup of the population involved does present a serious risk to health. Hypoxic pulmonary hypertension is also a common finding in chronic lung disease, leading to right heart failure and importantly contributing to the morbidity and mortality (Naeije and Dedobbeleer 2013, Scherrer et al. 2013, Wang et al. 2013). 
It is now generally accepted that inappropriate activation of the renin-angiotensin system (RAS) importantly contributes to the development of arterial hypertension and end-organ damage (Mitchell and Navar 1990, Hall and Brands 2000, Kobori et al. 2007, Gonzalez-Vilalobos et al. 2013, Bernstein et al. 2014, Navar 2014). RAS has been initially conceived as an endocrine system, with circulating angiotensin II (ANG II) as the major biologically active peptide hormone, and renin and angiotensin-converting enzyme (ACE) are two key enzymes responsible for ANG II production. ANG II-mediated activation of ANG II type 1 $\left(\mathrm{AT}_{1}\right)$ receptors was initially thought to be responsible for all physiological and pathophysiological actions of RAS (Mitchell and Navar 1990). Later on, this initial concept had to be dramatically modified and extended.

First, it is now recognized that a local organspecific RAS exist and its activity is regulated independently from the "classical" circulating RAS, in an autonomous way in each tissue (Paul et al. 2006, Castrop et al. 2010, Bernstein et al. 2014, Navar 2014). Within the new concept, it is hypothesized that uncontrolled activation of this local RAS and its pleotropic actions play a critical role in the development and progression of fibrotic/hypertrophic diseases (Kobori et al. 2007, Bernstein et al. 2014, Navar 2014).

Second, accumulating evidence shows that angiotensin-1-7 (ANG 1-7), a newly identified heptapeptide, exerts important vasoactive actions, and that the recently discovered ACE type 2 (ACE 2) is the most important ANG 1-7-forming enzyme, with the G protein-coupled Mas as a functional receptor for ANG 1-7 (Burgelová et al. 2005, 2009, Prieto et al. 2011, Santos et al. 2014). These discoveries provided a background for a new concept of the RAS as a dual axis system: the traditional axis represented by $\mathrm{ACE} / \mathrm{ANG} \mathrm{II} / \mathrm{AT}_{1}$ receptor, which is mainly vasoconstrictor, and the new ACE2/ANG 1-7/Mas receptor axis, which is vasodepressor (Ferrario 2011, Xu et al. 2011, Bader 2013). In addition, based on recent findings it has been proposed that the ACE2/ANG 1-7/ Mas receptor axis acts as counterbalancing factor of the deleterious actions of the $\mathrm{ACE} / \mathrm{ANG} \mathrm{II} / \mathrm{AT}_{1}$ receptor axis, especially under pathological conditions (Passos-Silva et al. 2013, Santos et al. 2013). Moreover, recent studies indicate that the role of $\mathrm{ACE} 2 / \mathrm{ANG} 1-7 / \mathrm{Mas}$ receptor axis is not limited to such counterregulatory role, but the axis exerts independent cardiovascular, renal and metabolic actions (Santos et al. 2013, 2014).
With regard to the pathogenesis of pulmonary hypertension, the role of intrapulmonary RAS would be of great interest. However, effects of chronic hypoxia on the activity of this local RAS have not been clearly established and the role of the RAS in the development of pulmonary hypertension in response to chronic hypoxia remains unknown. It is now accepted that ANG II does not mediate hypoxic pulmonary vasoconstriction but facilitates this response (Sylvester et al. 2012). It has been established that all major components of both RAS axes are expressed in lung tissue (Marshall 2003, Kaparianos and Argyropoulou 2011) and it has been recently shown that upregulation combined with endogenous activation of ACE2 with subsequent increase in intrapulmonary ANG 1-7 protect against the development of right ventricle hypertrophy in animal models of pulmonary hypertension and lung fibrosis (Shenoy et al. 2011, Kleinsasser et al. 2012, Li et al. 2013). Based on these studies, it has been proposed that intrapulmonary activation of ACE2/ANG 1-7/Mas receptor axis might be a promising therapeutic target for pulmonary hypertension (Shenoy et al. 2011). Nevertheless, studies evaluating the role of the RAS in hypoxic pulmonary hypertension have yielded inconsistent results (Berkov 1974, Hales et al. 1977, Suggett et al. 1980, McMurtry 1984, Kay et al. 1985, Oparil et al. 1988, Rabinovitch et al. 1988, Morrell et al. 1995, Herget et al. 1996, Kreutz et al. 1996, Zhao et al. 1996, Ward and McMurtry 2009, Camelo et al. 2012, de Man et al. 2012). Therefore, the role of RAS in the pathophysiology of hypoxic pulmonary hypertension remains controversial and is the focus of continuing research.

In view of the aforementioned knowledge, we hypothesized that increased intrapulmonary activity of the vasoconstrictor $\mathrm{ACE} / \mathrm{ANG} \mathrm{II/ \textrm {AT } _ { 1 }}$ receptor axis combined with a lack of compensatory activation of vasodilatory ACE2/ANG 1-7/Mas receptor axis of the RAS promotes the development of the hypoxic pulmonary hypertension. To test this hypothesis, we examined the effects of chronic hypoxia on the development of pulmonary hypertension in Ren-2 renin transgenic rat strain (TGR). TGR represent a unique welldefined monogenetic model of hypertension, in which hypertension is clearly related to the insertion of a mouse Ren-2 renin gene into the genome of normotensive Hannover Sprague-Dawley (HanSD) rats (Mullins et al. 1990). TGR exhibit increased tissue concentrations of ANG II, also in the lung (Campbell et al. 1995, Peters et 
al. 1996, Kreutz et al. 1998, Husková et al. 2006). In our opinion, studies using this model should help evaluate the precise nature of the relationship between the enhanced intrapulmonary activity of the endogenous RAS and the effects of exposure to chronic hypoxia in the pathophysiology of hypoxic pulmonary hypertension. Therefore, expressions of individual components of the RAS and their activities/concentrations in the lung tissue were determined in TGR and HanSD rats, both under normoxic conditions and after exposure to chronic hypoxia. Given the importance of the interaction of RAS with other vasoactive systems, such as endothelin (ET) and sympathetic nervous systems, in the mediation of cardiovascular responses to chronic hypoxia (DiCarlo et al. 1995, Hu et al. 1998, Shimoda and Laurie 2013), we also evaluated lung tissue catecholamines and endothelin-1 (ET-1) levels of TGR and HanSD rats, both under normoxic conditions or after exposure to chronic hypoxia.

\section{Materials and Methods}

The studies were performed in accordance with guidelines and practices established by the Animal Care and Use Committees of the Institute for Clinical and Experimental Medicine and of the $2^{\text {nd }}$ Faculty of Medicine, Charles University, Prague, Czech Republic.

\section{Animals}

All animals used in the present study were bred at the Center for Experimental Medicine from stock animals supplied from Max Delbrück Center for Molecular Medicine, Berlin, Germany (we acknowledge the generous gift of Drs. Bader and Ganten). The TGR rat strain was constructed by inserting the mouse Ren-2 renin gene, including $5 \mathrm{~kb}$ of 5 -flanking sequences and $9 \mathrm{~kb}$ 3 -flanking sequences into the rat genome of HanSD rats. Heterozygous TGR were generated by breeding male homozygous TGR with female homozygous HanSD rats as described and verified in the original study (Mullins et al. 1990). Animals were fed a standard rat chow containing $0.4 \%$ sodium chloride (SEMED, Prague, Czech Republic), with free access to tap water.

\section{Experimental design}

Series 1: Effects of chronic hypoxia on mean pulmonary artery pressure (MPAP) in TGR and HanSD rats

Between the days of age 66 and 80 (for 14 days) the animals were exposed to chronic normobaric hypoxia $\left(10 \% \mathrm{O}_{2}\right)$ using isobaric hypoxic chamber as described in detail in our previous studies (Hampl et al. 1993, 2003, Herget et al. 1996) and control groups were maintained on continuous normoxia. The following experimental groups were examined:

1. $\mathrm{TGR}+$ hypoxia $(\mathrm{n}=10)$

2. $\mathrm{TGR}+$ normoxia $(\mathrm{n}=9)$

3. HanSD + hypoxia $(n=8)$

4. HanSD + continuous normoxia $(n=8)$

At the end of experiments, animals were anesthetized with sodium thiopental $(30 \mathrm{mg} / \mathrm{kg}$, i.p.) and measurements of hemodynamic parameters were performed by methods described in detail previously (Herget and Paleček 1972, Hampl et al. 1993, 2003, Herget et al. 1996). Briefly, the pulmonary artery was catheterized via the left jugular vein and MPAP was recorded. Thereafter the rats were intubated via a tracheostomy and mechanically ventilated at $\sim 65$ breaths/min with room air (peak inspiratory pressure of $9 \mathrm{~cm} \mathrm{H}_{2} \mathrm{O}$, and expiratory pressure 0 ). The chest was opened at the midline and an ultrasonic flow probe was placed around the ascending aorta to estimate cardiac output (Transonic Systems, Altron Medical Electronic GmbH, Germany). This method is known to underestimate the in vivo values of cardiac output measured with intact chest and spontaneous breathing, but the error is likely similar in all animals and thus this approach allows reliable comparisons between control and experimental groups (Hampl et al. 1993). The cardiac index was calculated as the ratio of cardiac output divided by body weight (BW). After obtaining this value, the animals were killed with a lethal dose of thiopental sodium. Right heart ventricle (RV) was separated from left ventricle plus septum and weighed in a wet state as described previously (Herget and Paleček 1972, Hampl et al. 1993, 2003, Herget et al. 1996). For assessment of RV cardiac hypertrophy, the ratio of RV weight (RVW) to tibia length (TL) was employed because it has been shown that TL is independent of changes in body weight, and the above ratio is the most suitable index for assessment of cardiac hypertrophy under conditions when significant changes in BW occur (Vaňourková et al. 2006, Husková et al. 2010, Honetschlagerová et al. 2013). Analysis of right ventricular fibrosis was performed by histomorphometry using a Nikon Eclipse Ni-E light microscope and Nikon NIS-Elements AR 3.1 morphometric program (Nikon, Tokyo, Japan). Sections stained with Picrosirius red were photographed with a $20 \mathrm{x}$ objective in transmitted light to determine total 
tissue area and subsequently in polarized light to display areas occupied by collagen. The degree of RV fibrosis was expressed as the percentage of tissue area occupied by collagen compared to the total tissue surface, as reported previously (Whittaker et al. 1994).

Series 2: Effects of chronic hypoxia on expression and activities of individual components of the RAS, and on ET-1, epinephrine, norepinephrine and dopamine levels in lung tissue

In this series TGR and HanSD rats were subjected to the same protocol as animals in series 1 . The following experimental groups were examined:

1. TGR + hypoxia $(n=9)$

2. $\mathrm{TGR}+$ normoxia $(\mathrm{n}=10)$

3. HanSD + hypoxia $(n=9)$

4. HanSD + normoxia $(n=10)$

Since it is now well recognized that ANG II concentrations in anesthetized animals are higher than those obtained from decapitated conscious rats, and that normotensive animals exhibit greater increases in renin secretion in response to anesthesia and surgery than do ANG II-dependent hypertensive animals (Husková et al. 2006), in the present study rats from each experimental group were decapitated at the age of 80 days (i.e. on day 14 of exposure to hypoxia) and lung tissue samples were collected. This approach which is routinely used in our laboratory allows comparison of the present results with those of our previous studies performed to evaluate the role of the RAS in the pathophysiology of hypertension and end-organ damage (Husková et al. 2006, 2010, Vaňourková et al. 2006, Honetschlagerová et al. 2013, Varcabová et al. 2013). Lung tissue renin, ACE, and ACE2 activities and angiotensin I (ANG I), ANG II and ANG 1-7 levels and lung tissue concentrations of ET-1 and catecholamines were measured as described previously (Vaňourková et al. 2006, Husková et al. 2010, Honetschlagerová et al. 2013, Varcabová et al. 2013). In addition, rat and mouse renin gene, the expression of $\mathrm{AT}_{1}$ receptor and G-protein-coupled receptor Mas gene and ACE and ACE2 gene expression in the lung tissue were determined as described previously (Vaňourková et al. 2006, Nogueira et al. 2007, Burgelová et al. 2009, Husková et al. 2010, Honetschlagerová et al. 2013, Varcabová et al. 2013). Briefly, total RNA was extracted from lung tissue using TRIzol ${ }^{\circledR}$ Reagent (Life Technologies, Prague, Czech Republic) according to the manufacturer's directions. DNase I (Fermentas,
Thermoscientific, Waltham, MA, USA)-treated total RNA was reverse transcribed and amplified using One Step SYBR ${ }^{\circledR}$ PrimeScript $^{\mathrm{TM}}$ RT-PCR Kit II (TAKARA BIO INC, Shiga, Japan) in the total volume of $20 \mu \mathrm{l}$. All samples were analyzed in triplicates. The primers were designed by Primer3 software. Primer sequences were: rRen1 (rat renin):

forward 5'-GGCTGTTGATGGAGTCATCC-3' reverse 5'-AGCCGGCCTTGCTGAT-3'

mRen2 (mouse renin):

forward: 5'-GCCTCAGCAAGACTGATTCC-3' reverse: 5'-ATATTCATGTAGTCTCTTCTCC-3' $\mathrm{AT}_{1}$ receptor: forward: 5'-CCAAGATGACTGCCCCAAG-3' reverse: 5'-ATCACCACCAAGCTGTTTCC-3' $\beta$-actin:

forward: 5'-TGACTGACTACCTCATGAAGA-3' reverse: 5'-CACGTCACACTTCATGATG-3'

ACE:

forward: 5'-TCCTATTCCCGCTCATCTGC-3' reverse: 5'-CCAGCCCTTCTGTACCATT-3' ACE2:

forward: 5'-GAATGCGACCATCAAGCGTC-3' reverse: 5'-CAAGCCCAGAGCCTACGAT-3'

Mas receptor:

forward: 5'-CCTGCATACTGGGAAGACCA-3' reverse: 5'-TCCCTTCCTGTTTCTCATGG-3'

PCR amplifications were performed using the Light Cycler ${ }^{\circledR} 96$ Real-Time PCR System (Roche, Prague, Czech Republic) following the reaction parameters recommended by the manufacturer, using $2 \mathrm{mg}$ RNA per sample. $\beta$-actin was used as an endogenous control gene and negative controls contained water instead of cDNA. In all experiments, relative gene expression was calculated by the $\Delta$ cycle threshold $(\mathrm{Ct})$ method. Briefly, the resultant mRNA was normalized to a calibrator; in each case, the calibrator chosen was a group of HanSD rats on continuous normoxia. Final results were expressed as the n-fold difference in gene expression relative to $\beta$-actin mRNA

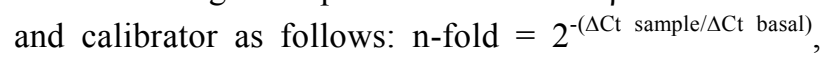
where $\Delta \mathrm{Ct}$ values of the sample and calibrator were determined by subtracting the average $\mathrm{Ct}$ value of the transcript under investigation from the average $\mathrm{Ct}$ value of the $\beta$-actin mRNA gene for each sample (Nogueira et al. 2007). Lung tissue concentrations of ET-1, epinephrine, norepinephrine and dopamine were analyzed by ELISA employing commercially available kits (Tricat ELISA, IBL International, and $\mathrm{GmbH}$, 
Germany), in accordance with the manufacturer's instructions. Again, the ratio RVW/TL was assessed.

\section{Statistical analysis}

All values are expressed as means \pm SEM. Using Graph-Pad Prism software (Graph Pad Software, San Diego, CA, USA), statistical analysis was performed by Student's $t$-test, Wilcoxon's signed-rank test for unpaired data, or one-way analysis of variance (ANOVA) when appropriate. Values exceeding the $95 \%$ probability limits $(\mathrm{P}<0.05)$ were considered statistically significant.

\section{Results}

Series 1: Effects of chronic hypoxia on MPAP in TGR and HanSD rats

As shown in Figure 1A, the data from hemodynamic studies reveal, that under continuous normoxia there were no significant differences in MPAP between TGR and HanSD rats (18.6 \pm 1.4 vs. $17.7 \pm 0.8$ $\mathrm{mm} \mathrm{Hg}$ ) and that the 14 days' exposure to hypoxia resulted in significant increases in MPAP in TGR (to $25 \pm 1.4 \mathrm{~mm} \mathrm{Hg}$ ) as well as in HanSD rats (to $30.4 \pm 1.6$ $\mathrm{mm} \mathrm{Hg}$ ) (in both cases different from normoxia at $\mathrm{P}<0.05$ ). However, the increases in MPAP in response to hypoxia were significantly smaller in TGR than in HanSD rats $(+6.4 \pm 0.7$ vs. $+12.7 \pm 0.9 \mathrm{~mm} \mathrm{Hg}, \mathrm{P}<0.05)$. There was no significant difference in BW between TGR and HanSD rats maintained under continuous normoxia $(329 \pm 12$ vs. $341 \pm 9 \mathrm{~g})$ and the two weeks' exposure to hypoxia elicited similar decreases in BW in TGR and in HanSD rats (to $240 \pm 8$ and to $238 \pm 4 \mathrm{~g}$, in both cases different from normoxia at $\mathrm{P}<0.05$ ).

As shown in Figure 1B, there was no sign of RV hypertrophy [RVW/TL ratio] in TGR as compared with HanSD rats maintained under continuous normoxia (5.81 \pm .10 vs. $6.22 \pm 0.14$ ). Chronic hypoxia caused RV hypertrophy in both the TGR and HanSD rats, but its magnitude was significantly smaller in the former (6.99 \pm 0.17 vs. $7.61 \pm 0.16, \mathrm{P}<0.05)$.

As shown in Figure 1C, among rats maintained in continuous normoxia, TGR showed the index (\%) of cardiac fibrosis significantly higher than observed in HanSD rats. Chronic hypoxia significantly decreased cardiac fibrosis in TGR and HanSD rats to similar levels. The images for representative slices of the right ventricular myocardium are shown for all groups in Figure 2.
A
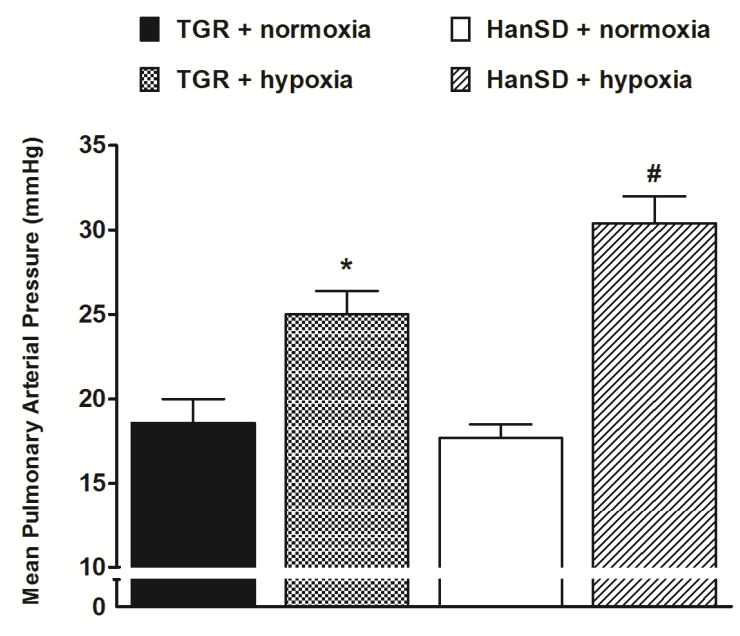

B
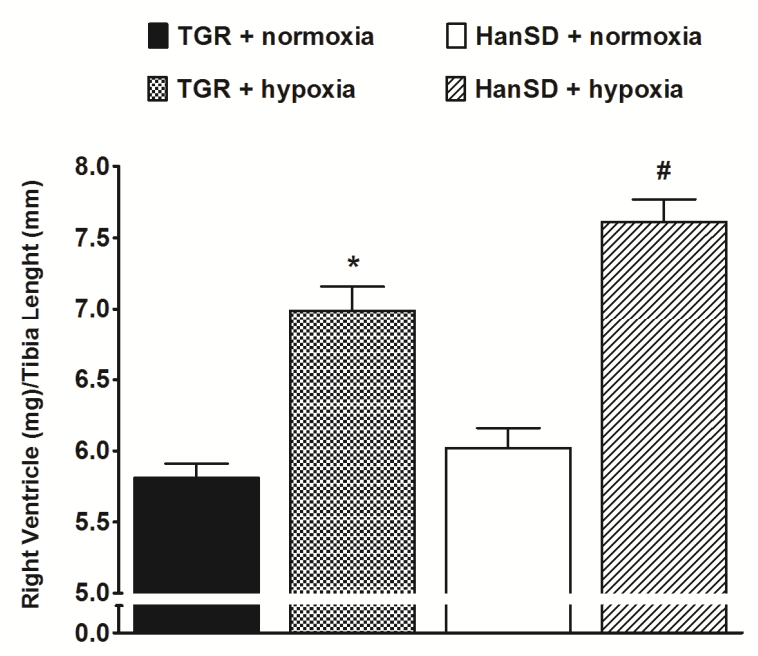

C

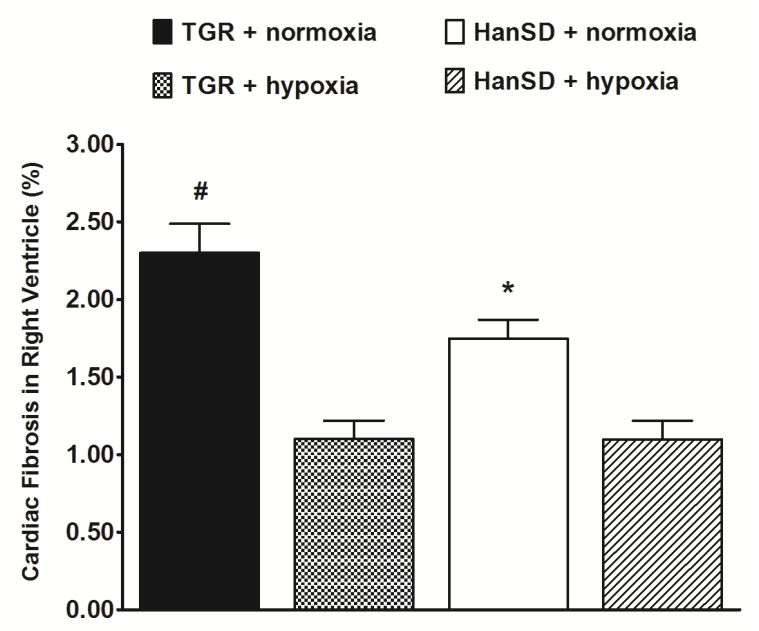

Fig. 1. Mean pulmonary arterial pressure (A), the ratio of right ventricle to tibia length (B), and cardiac fibrosis in right ventricle (C) after 14 days' exposure to chronic hypoxia (on day 80 of age) in TGR (heterozygous Ren-2 renin transgenic rats) or HanSD (transgene-negative) rats, compared with TGR and HanSD rats maintained under continuous normoxia. Values are means \pm SEM. $* \mathrm{P}<0.05$ vs. unmarked values; ${ }^{\#} \mathrm{P}<0.05$ vs. all the other values. 

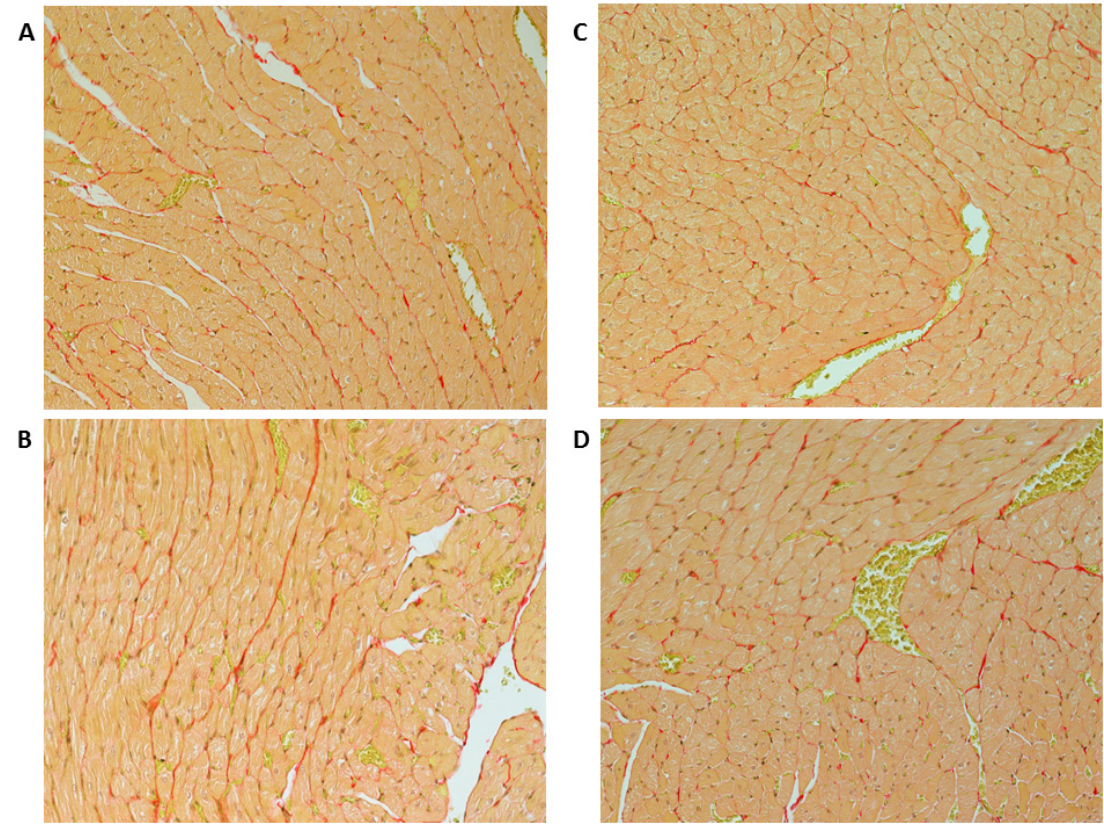

Fig. 2. Representative images from slices of picrosirius red staining of the right ventricular myocardium in TGR (heterozygous Ren-2 renin transgenic rats) under conditions of continuous normoxia (A), in TGR exposed to chronic hypoxia (B), and in HanSD (transgene-negative) rats under conditions of continuous normoxia (C), and in HanSD exposed to chronic hypoxia (D). The images show only minimal interstitial collagen deposition without significant differences between the two rat strains; nor was there any demonstrable increase in the staining after hypoxiainduced pulmonary hypertension (original magnification 200x).
Series 2: Effects of chronic hypoxia on expression and activities of individual components of the RAS, and on ET-1, epinephrine, norepinephrine and dopamine levels in lung tissue

As shown in Figure 3A, under continuous normoxia ANG II concentrations in lung tissue were significantly higher in TGR than in HanSD rats $(281 \pm 34$ vs. $75 \pm 27 \mathrm{fmol} / \mathrm{g}, \mathrm{P}<0.05)$. In TGR the exposure to hypoxia decreased lung ANG II to levels observed in HanSD rats in which hypoxia was without effect. As shown in Figure 3B, under continuous normoxia lung renin activity was markedly higher in TGR than in HanSD rats $\left(34.2 \pm 4.5\right.$ vs. $11.9 \pm 0.9 \mathrm{ng}$ ANG $\mathrm{I}_{\mathrm{ml}} \mathrm{m}^{-1} \cdot \mathrm{h}^{-1}$, $\mathrm{P}<0.05)$. Neither value was altered by exposure to chronic hypoxia. As shown in Figures 3C and 3D, lung ACE activity measured directly or estimated as the ratio of ANG II to ANG I did not significantly differ between TGR and HanSD rats maintained under continuous normoxia; however, exposure to hypoxia significantly decreased ACE activity in TGR and did not alter it in HanSD rats.

As shown in Figure 3E, under continuous normoxia ANG 1-7 concentrations in lung tissue were not significantly different in TGR as compared with HanSD rats. The exposure to chronic hypoxia did not alter ANG 1-7 concentrations in lung tissue of HanSD rats, but elicited a significant increase in TGR $(61 \pm 8$ vs. $14 \pm 5 \mathrm{fmol} / \mathrm{g}, \mathrm{P}<0.05)$. As shown in Figure $3 \mathrm{~F}$, lung ACE2 activity exhibited a concentration pattern similar as that observed for lung ANG 1-7: no difference between TGR and HanSD rats under continuous normoxia, and exposure to chronic hypoxia increasing ACE2 activity in TGR but not in HanSD rats.

As shown in Figure 4A, there were no significant differences in lung rat renin gene expression between TGR and HanSD rats under continuous normoxia, and chronic hypoxia did not change it significantly. Likewise, chronic hypoxia did not change lung mouse renin gene expression in TGR (Fig. 4B).

As shown in Figure 4C, there were no significant differences in lung ACE gene expression between TGR and HanSD rats under continuous normoxia. The exposure to chronic hypoxia did not alter these values in HanSD rats, but caused a significant decrease in lung ACE gene expression in TGR.

As shown in Figure 4D, lung ACE2 gene expression was similar in TGR and HanSD rats under continuous normoxia. The exposure to chronic hypoxia did not modify this value in HanSD rats, but elicited a marked increase in lung ACE2 gene expression in TGR.

As shown in Figure 4E, lung tissue of $\mathrm{AT}_{1}$ receptor gene was significantly higher in TGR than in HanSD rats maintained under continuous normoxia, and exposure to chronic hypoxia decreased the expression in TGR and did not alter it in HanSD rats.

As shown in Figure 4F, there were no significant differences in lung tissue Mas receptor gene expression between TGR and HanSD rats maintained under continuous normoxia, and exposure to chronic hypoxia elicited a significant increase in the expression in TGR but did not alter it in HanSD rats. 
A

— TGR + normoxia $\square$ HanSD + normoxia

圈 TGR + hypoxia $\oslash$ HanSD + hypoxia

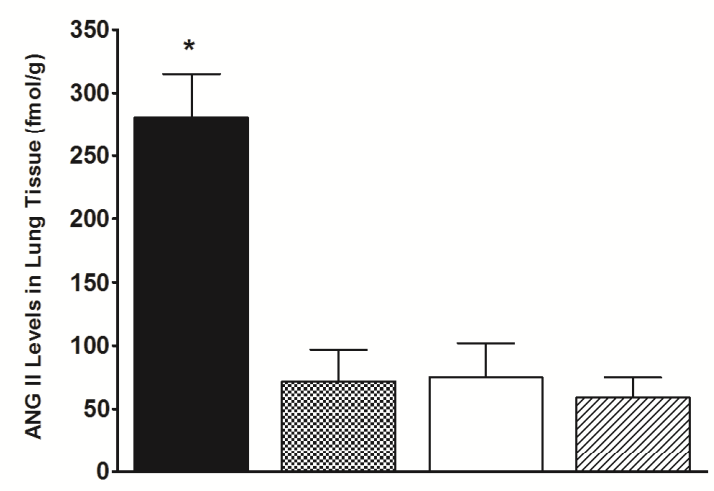

B

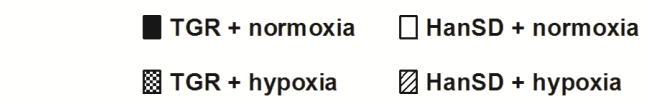

C
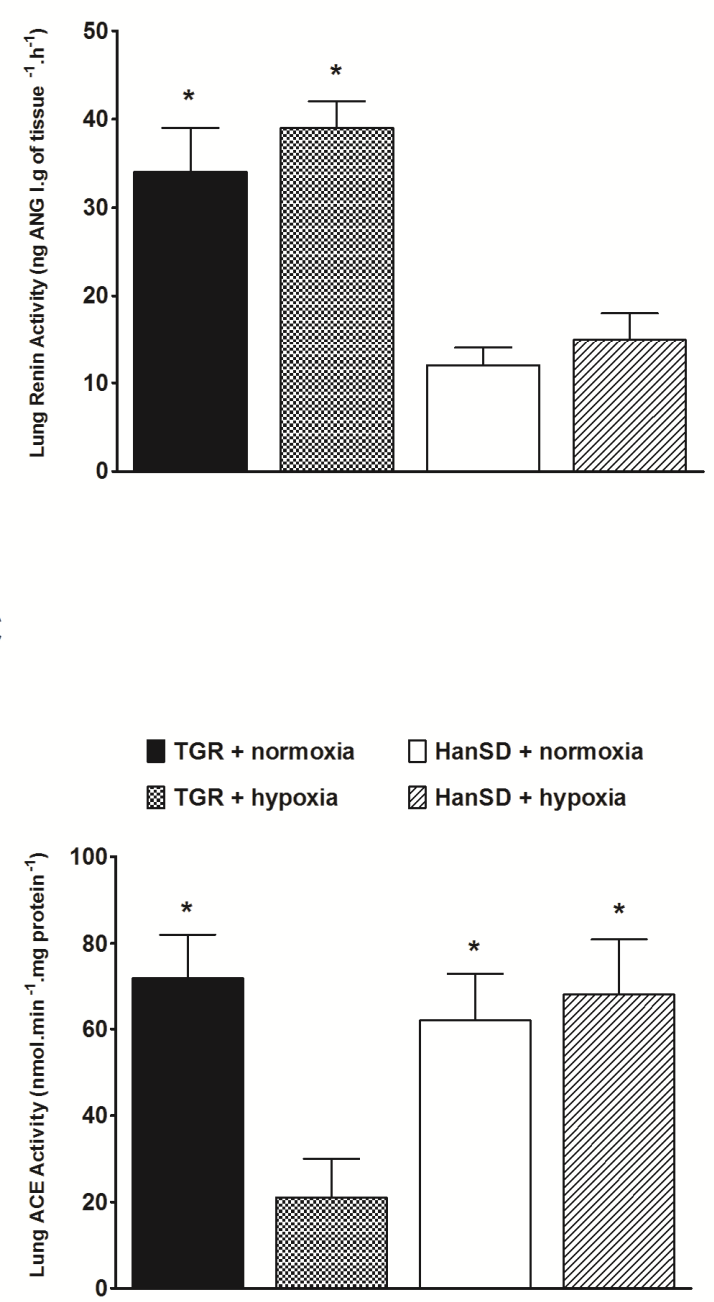

D

$\begin{array}{ll}\square \text { TGR + normoxia } & \square \text { HanSD + normoxia } \\ \text { T TGR + hypoxia } & \square \text { HanSD + hypoxia }\end{array}$

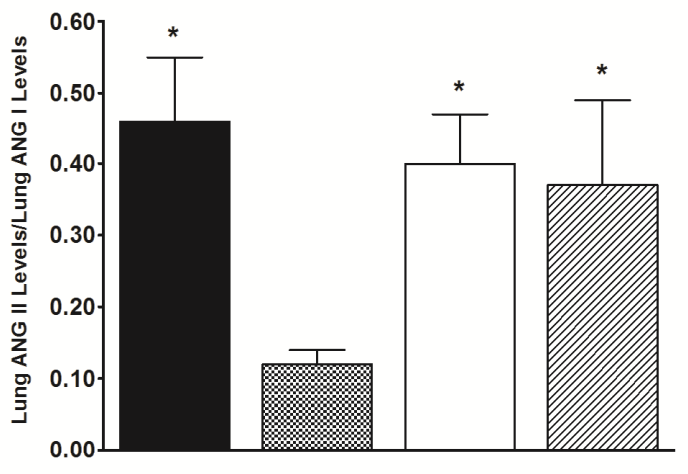

E

TGR + normoxia $\square$ HanSD + normoxia

圈 TGR + hypoxia $\oslash$ HanSD + hypoxia

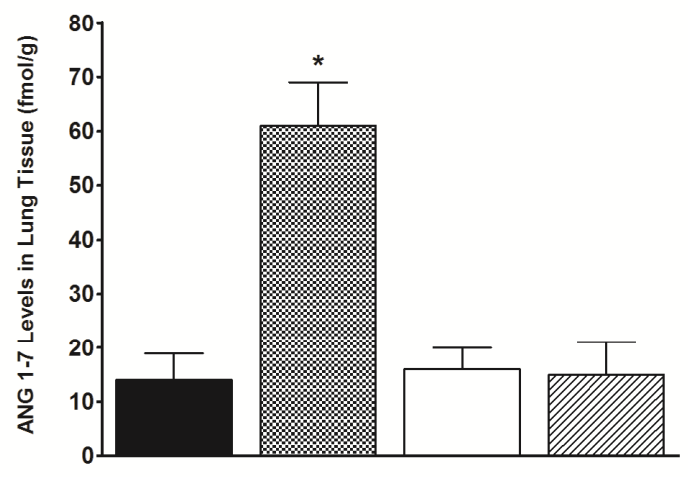

$\mathbf{F}$

Fig. 3. Lung angiotensin II (ANG II) levels (A), lung renin activity (B), lung angiotensin-converting enzyme (ACE) activity (C) and the ratio of lung ANG II to angiotensin I (ANG I) levels (D), lung angiotensin 1-7 (ANG 1-7) levels (E) and lung angiotensin-converting enzyme type 2 (ACE2) activity (F) in TGR (heterozygous Ren-2 renin transgenic rats) and HanSD (transgene-negative) rats. Values are means \pm SEM. $* \mathrm{P}<0.05$ vs. unmarked values. 
A

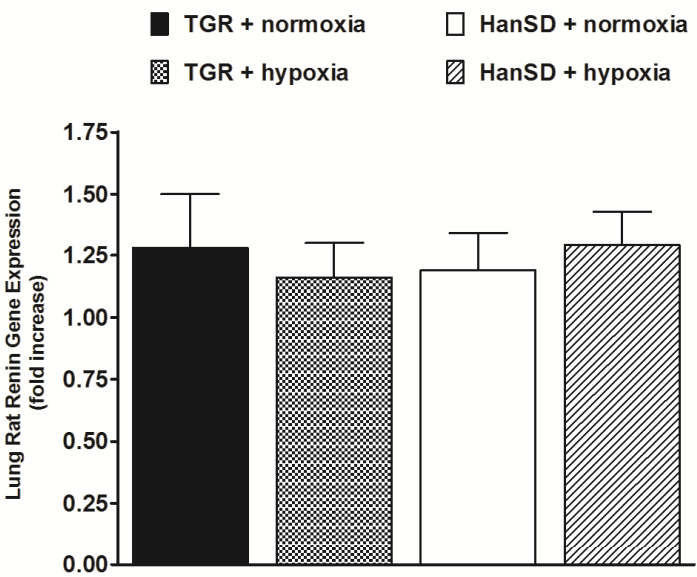

B

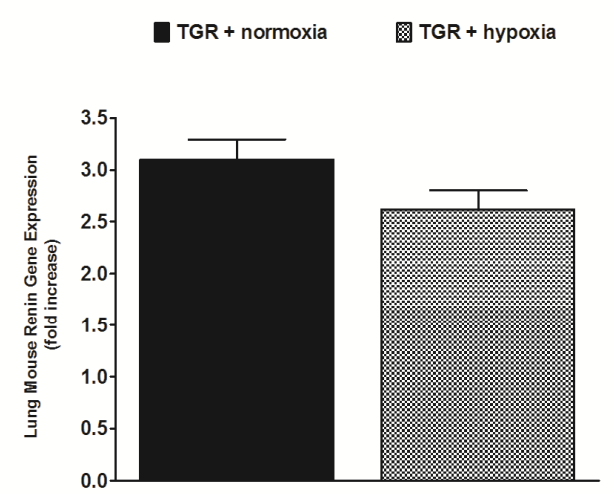

C

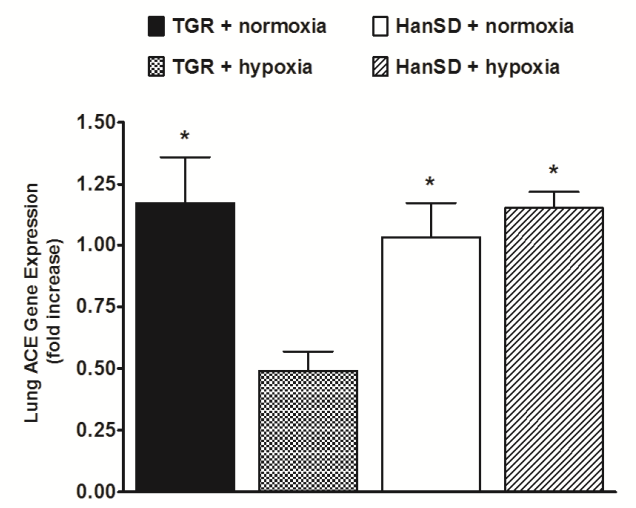

D
TGR + normoxia
$\square$ HanSD + normoxia
圈 TGR + hypoxia
$\square$ HanSD + hypoxia

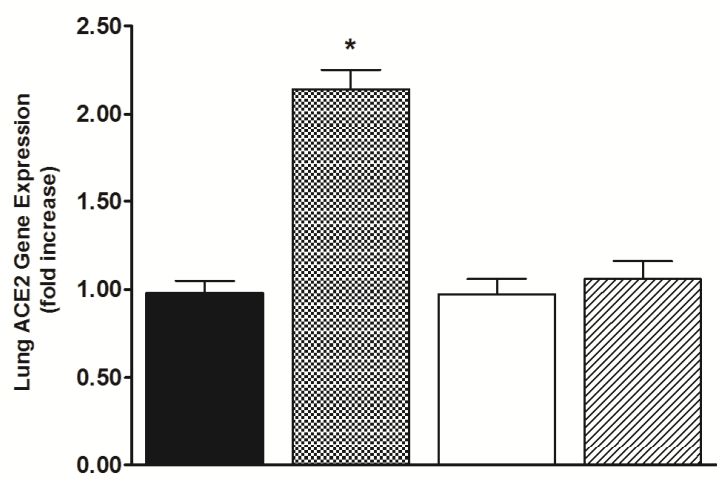

E
娄 TGR + hypoxia HanSD + hypoxia

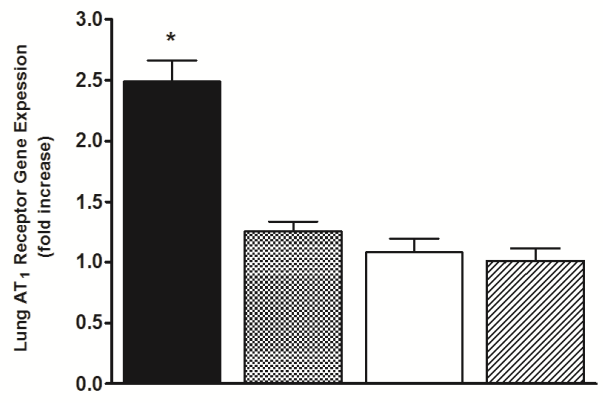

F

Fig. 4. The expression in lung tissue of rat (A) and mouse (B), renin genes for angiotensin-converting enzyme (ACE), and the expression in lung tissue of angiotensin-converting enzyme genes for ACE (C) and ACE 2 (D), lung ANG II type 1 (AT 1 ) receptor gene expression (E), and lung Mas receptor gene expression (F) in TGR (heterozygous Ren-2 renin transgenic rats) and HanSD (transgene-negative) rats. Values are means \pm SEM. $*$ P $<0.05$ vs. unmarked values in TGR (heterozygous Ren-2 renin transgenic rats) and HanSD (transgenenegative) rats. Values are means $\pm \mathrm{SEM} . * \mathrm{P}<0.05$ vs. unmarked values. 
A
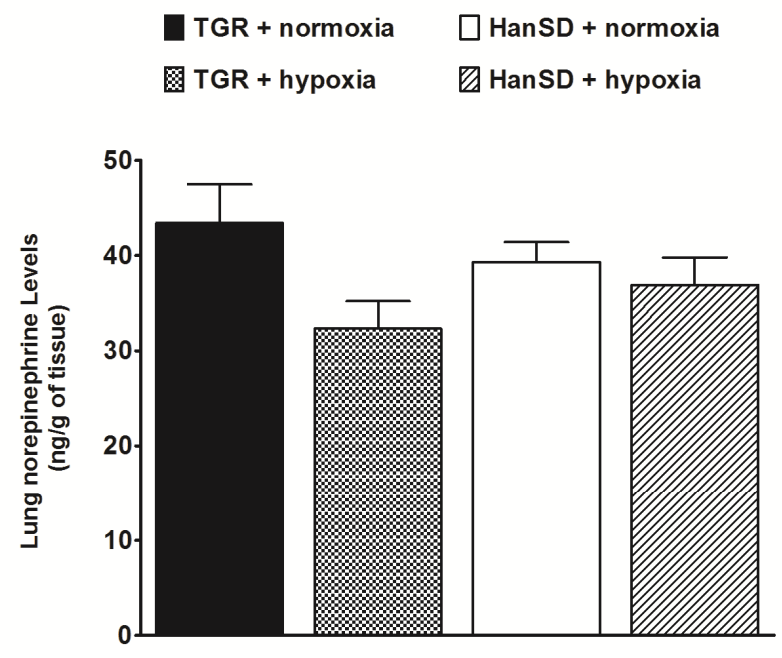

B

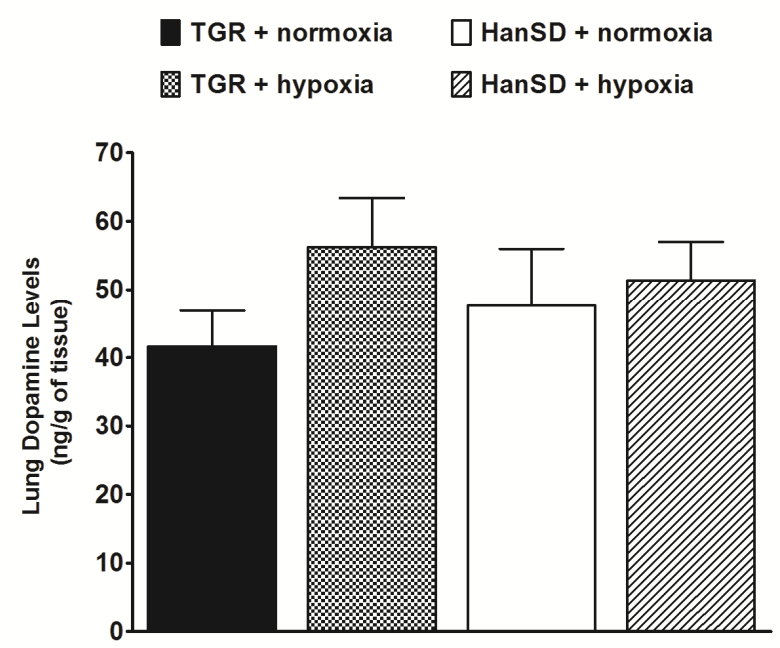

C

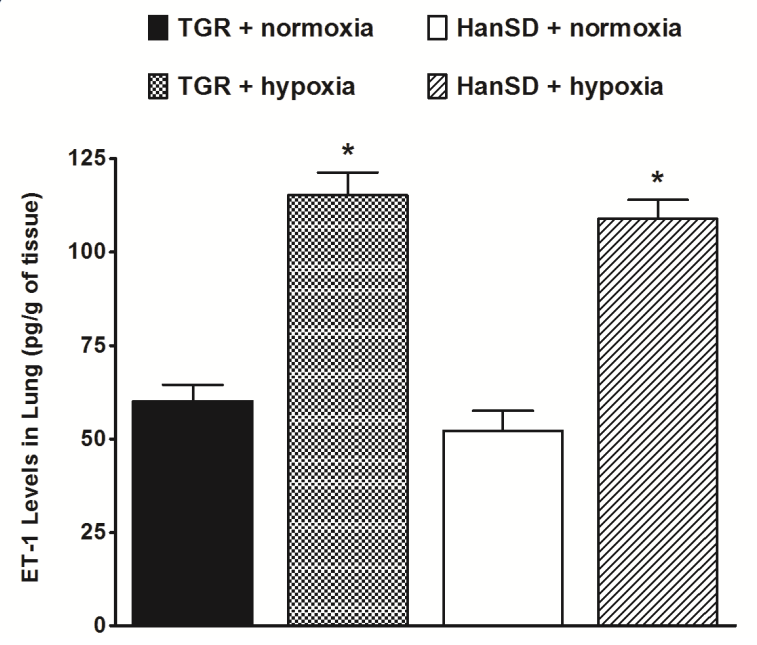

Fig. 5. Lung tissue norepinephrine (A), dopamine (B) and endothelin 1 (ET-1) levels (C) in TGR (heterozygous Ren-2 renin transgenic rats) and HanSD (transgene-negative) rats). Values are means $\pm \mathrm{SEM}$. $* \mathrm{P}<0.05$ vs. unmarked values.
As shown in Figures $5 \mathrm{~A}$ and $5 \mathrm{~B}$, there were no significant differences in lung norepinephrine and dopamine levels between TGR and HanSD rats maintained under continuous normoxia. Nor were these values significantly changed by exposure to chronic hypoxia. As shown in Figure 5C, there were no significant differences in lung ET-1 tissue concentrations between TGR and HanSD rats under continuous normoxia $(60.1 \pm 4.4$ vs. $52.2 \pm 5.4 \mathrm{pg} / \mathrm{g})$. The exposure to chronic hypoxia caused significant and similar increases in these values both in TGR and in HanSD rats (to $115.2 \pm 6.1$ and $108.9 \pm 5.1 \mathrm{pg} / \mathrm{g}$ ).

\section{Discussion}

The major new finding of this study is that in TGR a two weeks' exposure to hypoxia did not increase pulmonary hypertension more than was seen in transgene-negative normotensive HanSD rats. In fact, the increases in MPAP in response to chronic hypoxia were significantly smaller in TGR as compared with HanSD rats.

In this regard the most important question of our present study is: what are the mechanism(s) responsible for the attenuated MPAP response to chronic hypoxia in TGR as compared with HanSD rats?

We saw that chronic hypoxia did not alter lung ANG II concentration in HanSD rats but substantially reduced them in TGR, down to levels found in HanSD rats. Since ANG II facilitates hypoxic pulmonary vasoconstriction (Berkov 1974, Hales et al. 1977, Sylvester et al. 2012), it can be reasoned that attenuation of hypoxic pulmonary hypertension in TGR as compared with the response in HanSD rats can be ascribed to the substantial suppression of lung ANG II concentration in the former. Chronic hypoxia did not suppress lung renin gene expression and activity but did suppress lung ACE gene expression and activity and lung $\mathrm{AT}_{1}$ receptor gene expression. These findings indicate that suppression of increased ANG II concentrations in lung tissue in response to chronic hypoxia is mediated by suppression of lung ACE activity, moreover, chronic hypoxia suppressed lung $\mathrm{AT}_{1}$ receptor gene expression in TGR. Considering the recent reports indicating that increased activity of ACE2/ANG 1-7/Mas receptor axis protects the circulatory system against the development of pulmonary hypertension induced by monocrotaline injection or by acute exposure to hypoxia (Kleinsasser et al. 2012, Li et al. 2013), our findings that lung ACE2 gene expression, 
lung ACE2 activity and especially lung ANG 1-7 concentrations and Mas receptor gene expression are markedly increased in TGR exposed to chronic hypoxia (but not in HanSD rats) are of critical importance. They provide sound evidence that activation of the ACE2/ANG 1-7/Mas receptor axis is decisive for attenuation of MPAP response to chronic hypoxia in TGR.

Since there were no significant differences in lung tissue concentrations of catecholamines between TGR and HanSD rats, both under conditions of continuous normoxia and after exposure to chronic hypoxia, it is unlikely that local changes in the activity of the sympathetic nervous system were responsible for the different pulmonary hypertensive responses to hypoxia in TGR vs. HanSD rats. Finally, our finding that in TGR and HanSD rats chronic hypoxia elicited significant increases in lung tissue ET-1 concentration are in agreement with the accepted notion that activation of ET system contributes to the development of pulmonary hypertension (DiCarlo et al. 1995, Hu et al. 1998, Shimoda and Laurie 2013). However, because the increases in lung tissue ET-1 were similar in TGR and HanSD rats, it is unlikely that activation of ET system should account for the observed difference in the development of hypoxic pulmonary hypertension between TGR and HanSD rats.

The second important finding of the present study is that under conditions of continuous normoxia TGR do not exhibit pulmonary hypertension and RV hypertrophy. This is in accordance with aforementioned studies suggesting that increased intrapulmonary RAS activity per se does not lead to the development of pulmonary hypertension (Krebs et al. 1999, Kaparianos et al. 2011, Lefebvre et al. 2011, Sylvester et al. 2012). On the other hand, our findings are at odds with the results reported recently by DeMarco et al. (2008, 2009), who found that TGR overexpressed Ren-2 renin gene in lung tissue and exhibited elevated RV systolic blood pressure (RVSP) as compared with control animals, also under conditions of continuous normoxia. We cannot offer a satisfactory explanation for these discrepancies, one reason could be the different methodology of estimating MPAP between the laboratory of DeMarco's and ours. We measure MPAP directly in rats with closed chest, a method that is generally accepted as a golden standard (Sylvester et al. 2012) whereas DeMarco's group employed RVSP as a marker of the degree of pulmonary hypertension, an indirect method that is, however, also commonly accepted (Sylvester et al. 2012). Thus, this difference in methodology might or might not be responsible for the different findings regarding MPAP in TGR rats. In this regard, it is intriguing that even though DeMarco et al. found markedly increased RVSP in TGR, they did not observe any sign of RV hypertrophy as compared with control animals (DeMarco et al. 2008, 2009).

The third interesting finding of our present study is that under conditions of normoxia our TGR and HanSD rats exhibited only minimal cardiac fibrosis and collagen deposition which were further reduced after exposure to chronic hypoxia. This indicates that the observed RV hypertrophy was not associated with increased cardiac fibrosis or collagen deposition, however, it cannot be excluded that such pathologic changes would develop with longer duration of pulmonary hypertension.

In summary, we showed that pulmonary hypertension induced by chronic hypoxia was distinctly less pronounced in TGR as compared with transgenenegative normotensive HanSD rats. The alleviation of pulmonary hypertensive response to hypoxia observed in TGR was associated with two sets of changes. On one hand, there was a suppression of ACE gene expression and activity, a decrease in the expression of $\mathrm{AT}_{1}$ receptor gene, and normalization of ANG II concentrations in lung tissue. On the other hand, we observed increased ACE2 gene expression and ACE2 activity and, perhaps most important, increased ANG 1-7 concentrations and Mas receptor expression in lung tissue.

Taken together, our present data suggest that a combination of suppression of ACE/ANG II/AT $\mathrm{AT}_{1}$ receptor axis and activation of ACE2/ANG 1-7/Mas receptor axis in the lung tissue is the main mechanism explaining attenuation of hypoxic pulmonary hypertension in TGR as compared with HanSD rats.

\section{Conflict of Interest}

There is no conflict of interest.

\section{Acknowledgements}

This study was principally supported by the grant No. NT/14085-5 awarded by the Internal Grant Agency of the Ministry of the Health of the Czech Republic to Z.H. and by the project of the Ministry of Health of the Czech Republic for the development of research organization 00023001 (IKEM) (institutional support). S.J. is supported by the Grant Agency of Charles University 
No. 266213. The Center for Experimental Medicine (IKEM) received financial support from the European Commission within the Operational Program Prague - Competitiveness; project "CEVKOON" (\#CZ.2.16/3.1.00/22126) and this study was also result of noncommercial cooperation between IKEM and
OMNIMEDICS Ltd. within the project "CEVKOON". J.H. and V.H. are supported by the grant \#13-01710S from the Grant Agency of the Czech Republic. J.H. is also supported by the grant NT/13358 awarded by the Internal Grant Agency of the Ministry of Health of the Czech Republic.

\section{References}

BADER M: ACE2, angiotensin-(1-7), and Mas: the other side of the coin. Pflugers Arch 465: 79-85, 2013.

BERKOV S: Hypoxic pulmonary vasoconstriction in the rat. The necessary role of angiotensin II. Circ Res 35 : 256-261, 1974.

BERNSTEIN KE, GIANI JF, SHEN XZ, GONZALEZ-VILALOBOS RA: Renal angiotensin-converting enzyme and blood pressure control. Curr Opin Nephrol Hypertens 23: 106-112, 2014.

BURGELOVÁ M, KRAMER HJ, TEPLAN V, THUMOVÁ M, CERVENKA L: Effects of angiotensin-(1-7) blockade on renal function in rats with enhanced intrarenal ANG II activity. Kidney Int 67: 1453-1461, 2005.

BURGELOVÁ M, VAŇOURKOVÁ Z, THUMOVÁ M, DVOŘÁK P, OPOČENSKÝ M, KRAMER HJ, ŽELÍZKO M, MALÝ J, BADER M, ČERVENKA L: Impairment of the angiotensin-converting enzyme 2-angiotensin-(1-7)Mas axis contributes to the acceleration of two-kidney, one-clip Goldblatt hypertension. J Hypertens 27: 19882000, 2009.

CAMELO JS JR, MARTINS AR, ROSA E, RAMOS SG, HEHRE D, BANCALARI E, SUGUIHARA C: Angiotensin II type 1 receptor blockade partially attenuates hypoxia-induced pulmonary hypertension in newborn piglets: relationship with the nitrergic system. Braz J Med Res 45: 163-171, 2012.

CAMPBELL DJ, RONG P, KLADIS A, REEES B, GANTEN D, SKINNER SL: Angiotensin and bradykinin peptides in the TGR(mRen-2)27 rat. Hypertension 25: 1014-1020, 1995.

CASTROP H, HOCHERL K, KURTZ A, SCHWEDA F, TOTOROV V, WAGNER C: Physiology of kidney renin. Physiol Rev 90: 607-673, 2010.

DE MAN FS, TU L, HANDOKO ML, RAIN S, RUITER G, FRANCOIS C, SCHALIJ I, DORFMULLER P, SIMONNEAU G, FADEL E, PERROS F, BOONSTRA A, POSTMUS PE, VAN DER VELDEN J, VONKNOORDEGRAAF A, HUMBERT M, EDDAHIBI S, GUIGNABERT C: Dysregulation renin-angiotensinaldosterone system contributes to pulmonary arterial hypertension. Am J Respir Crit Care Med 186: 780-789, 2012.

DEMARCO VG, HABIBI J, WHALEY-CONNELL AT, SCHNEIDER RI, HELLER RL, BOSANQUET JP, HAYDEN MR, DELCOUR K, COOPER SA, ANDRESEN BT, SOWERS JR, DELLSPERGER KC: Oxidative stress contributes to pulmonary hypertension in the transgenic (mRen2)27 rat. Am J Physiol 294: H2659-H2668, 2008.

DEMARCO VG, HABIBI J, WHALEY-CONNELL AT, SCHNEIDER RI, SOWERS JR, ANDRESEN BT, GUTWILER AA, MA L, JOHNSON MS, FERRARIO CM, DELLSPERGER KC: Rosuvastatin ameliorates the development of pulmonary arterial hypertension in the transgenic (mRen2)27 rat. Am J Physiol 297: H1128-H1139, 2009.

DICARLO VS, CHEN SJ, MENG QC, DURAND J, YANO M, CHEN YF: ET $_{\mathrm{A}}$-receptor antagonist prevents and reverses chronic hypoxia-induced pulmonary hypertension in rat. Am J Physiol 269: L690-L697, 1995.

FERRARIO CM: ACE2: more of Ang-(1-7) or less Ang II? Curr Opin Nephrol Hypertens 20: 1-6, 2011.

GONZALES-VILALOBOS RA, JANJOUILIA T, FLETECHER NK, GIANI JF, NGUYEN MT, RIQUIER-BRISON AD, SETH DM, FUCHS S, ELADARI D, PICARD N, BACHMANN S, DELPIRE E, PETI-PETERDI J, NAVAR LG, BERNSTEIN KE, MCDOUNOUGH AA: The absence of intrarenal ACE protects against hypertension. J Clin Invest 123: 2011-2023, 2013.

HALES CA, ROUSE ET, KAZEMI H: Failure of saralasin acetate, a competitive inhibitor of angiotensin II, to diminish alveolar hypoxic vasoconstriction in the dog. Cardiovasc Res 11: 541-546, 1977. 
HALL JE, BRANDS MW: The renin-angiotensin-aldosterone system: renal mechanisms and circulatory homeostasis. In: The Kidney: Physiology and Pathophysiology. SELDIN DW, GIEBISCH G (eds), Lippincott Williams \& Wilkins, Philadelphia, 2000, pp 1009-1046.

HAMPL V, ARCHER SL, NELSON DP, WEIR EK: Chronic EDRF inhibition and hypoxia: effects on pulmonary circulation and systemic blood pressure. J Appl Physiol 75: 1748-1757, 1993.

HAMPL V, BÍBOVÁ J, OŠŤÁDALOVÁ I, POVÝŠILOVÁ V, HERGET J: Gender differences in the long-term effects of perinatal hypoxia on pulmonary circulation in rats. Am J Physiol 285: L386-L392, 2003.

HERGET J, PALEČEK F: Pulmonary arterial blood pressure in closed chest rats. Changes after catecholamines, histamine and serotonin. Arch Int Pharmacodyn Ther 198: 107-117, 1972.

HERGET J, PELOUCH V, KOLÁŘ F, OŠŤÁDAL B: The inhibition of angiotensin converting enzyme attenuates the effects of chronic hypoxia on pulmonary blood vessels in the rat. Physiol Res 45: 221-226, 1996.

HONETSCHLAGEROVÁ Z, KITADA K, HUSKOVÁ Z, SPORKOVÁ A, KOPKAN L, BURGELOVÁ M, VARCABOVÁ Š, NISHIYAMA A, HWANG SH, HAMMOCK BD, IMIG JD, KUJAL P, VERNEROVÁ Z, ČERVENKA L: Antihypertensive and renoprotective actions of soluble epoxide hydrolase inhibition in ANG II-dependent malignant hypertension are abolished by pretreatment with L-NAME. J Hypertens 31: 321-332, 2013.

HU J, DISCHER DJ, BISHOPRIC NH, WEBSTER KA: Hypoxia regulates expression of the endothelin-1 gene through a proximal hypoxia-inducible factor-1 binding site on the antisens strand. Biochem Biophys Res Commun 245: 894-899, 1998.

HUSKOVÁ Z, KRAMER HJ, VAŇOURKOVÁ Z, ČERVENKA L: Effects of changes in sodium balance on plasma and kidney angiotensin II levels in anesthetized and conscious Ren-2 transgenic rats. J Hypertens 24: 517-527, 2006.

HUSKOVÁ Z, VAŇOURKOVÁ Z, ERBANOVÁ M, THUMOVÁ M, OPOČENSKÝ M, MULLINS JJ, KRAMER HJ, BURGELOVÁ M, ČERVENKA L: Inappropriately high circulating and intrarenal angiotensin II levels during dietary salt loading exacerbate hypertension in Cypla1-Ren-2 transgenic rats. J Hypertens 28: 495-509, 2010.

KAPARIANOS A, ARGYROPOULOU E: Local renin-angiotensin II systems, angiotensin-converting enzyme and its homologue ACE2: their potential role in the pathogenesis of chronic obstructive pulmonary diseases, pulmonary hypertension and acute respiratory syndrome. Curr Med Chem 18: 3506-3515, 2011.

KAY JM, KEANE PM, SUYAMA KL, GAUTHIER D: Lung angiotensin converting enzyme activity in chronically hypoxic rats. Thorax 40: 587-591, 1985.

KLEINSASSER A, PIRCHER I, TREML B, SCHWIENBACHTER M, SCHUSTER M, JANZEK E, LOIBNER H, PENNINGER JM, LOECKINGER A: Recombinant angiotensin-converting enzyme 2 suppresses pulmonary vasoconstriction in acute hypoxia. Wilderness Environ Med 23: 24-30, 2012.

KOBORI H, NANGAKU M, NAVAR LG, NISHIYAMA A: The intrarenal renin-angiotensin system: from physiology to the pathobiology of hypertension and kidney disease. Pharmacol Rev 59: 251-287, 2007.

KREBS MO, BOEMKE W, SIMON S, WEN M, KACZMARCZYK G: Acute hypoxic pulmonary vasoconstriction in conscious dogs decreases renin and is unaffected by losartan. J Appl Physiol 86: 1914-1919, 1999.

KREUTZ R, FERNANDEZ-ALFONSE MS, PAUL M, PETERS J: Effect of losartan on right ventricular hypertrophy and cardiac angiotensin I-converting enzyme activity in pulmonary hypertensive rats. Clin Exp Hypertens 18 : 101-111, 1996.

KREUTZ R, FERNANDEZ-ALFONSON MS, PAUL M, PETERS J: Differential development of early hypertension in heterozygous transgenic TGR(mRen2)27 rats. Clin Exp Hypertens 20: 273-282, 1998.

LEFEBVRE F, PRÉFONTAINE A, CALDERONE A, CARON A, JASMIN J-F, VILLENEUVE L, DUPUIS J: Modification of the pulmonary renin-angiotensin system and lung structure remodeling in congestive heart failure. Clin Sci 111: 217-227, 2006.

LI G, LIU Y, ZHU Y, LIU A, XU Y, LI Z, SU J, SUN L: ACE2 activation confers endothelial protection and attenuates neointimal lesions in prevention of severe pulmonary arterial hypertension in rats. Lung 191: 327-336, 2013.

MARSHALL RP: The pulmonary renin-angiotensin system. Curr Pharm Des 9: 715-722, 2003. 
MCMURTRY IF: Angiotensin is not required for hypoxic constriction in salt solution-perfused rat lung. $J$ Appl Physiol 56: 375-380, 1984.

MITCHELL KD, NAVAR LG: Intrarenal actions of angiotensin II in the pathogenesis of experimental hypertension. In: Hypertension: Pathophysiology, Diagnosis and Management. LARAGH JH, BRENNER BM (eds), New York, NY: Raven Press, Publishers, 1990, pp 1437-1452.

MORRELL NW, MORRIS KG, STENMARK KR: Role of angiotensin-converting enzyme and angiotensin II in the development of hypoxic pulmonary hypertension. Am J Physiol 38: H1186-H1194, 1995.

MULLINS JJ, PETERS J, GANTEN D: Fulminant hypertension in transgenic rats harboring the mouse Ren-2 gene. Nature 344: 541-544, 1990.

NAEIJE R, DEDOBBELEER C: Pulmonary hypertension and the right ventricle in hypoxia. Exp Physiol 98: 12471256, 2013.

NAVAR LG: Intrarenal renin-angiotensin system in regulation of glomerular function. Curr Opin Nephrol Hypertens 23: 38-45, 2014.

NOGUEIRA EF, VARGAS CA, OTIS M, GALLO-PAYET N, BOLLAG WB, RAINEY WE: Angiotensin-II acute regulation of rapid response genes in human, bovine, and rat adrenocortical cells. $J$ Mol Endocrinol 39: 365-374, 2007.

OPARIL S, NARKATES AJ, JACKSON RM, ANN HS: Altered angiotensin-converting enzyme in lung and extrapulmonary tissues of hypoxia-adapted rats. $J$ Appl Physiol 65: 218-227, 1988.

PASSOS-SILVA DG, VERANO-BRAGA T, SANTOS RAS: Angiotensin-(1-7): beyond the cardio-renal actions. Clin Sci 124: 443-456, 2013.

PAUL M, MEHR AP, KREUTZ R: Physiology of local renin-angiotensin systems. Physiol Rev 86: 747-803, 2006.

PETERS J, HILGERS KF, MASER-GLUTH C, KREUTZ R: Role of the circulating renin-angiotensin system in the pathogenesis of hypertension in transgenic rats TGR(mRen2)27. Clin Exp Hypertens 18: 933-948, 1996.

PRIETO MC, GONZÁLEZ-VILLALOBOS RA, BOTROS FT, MARTIN VL, PAGÁN J, SATOU R, LARA LS, FENG Y, FERNANDES FB, KOBORI H, CASARINI DE, NAVAR LG: Reciprocal changes in renal ACE/ANG II and ACE2/ANG 1-7 are associated with enhanced collecting duct renin in Goldblatt hypertensive rats. Am J Physiol 300: F749-F755, 2011.

RABINOVITCH M, MULLEN M, ROSENBERG HC, MARUYAMA K, O'BRODOVICH H, OLLEY PM: Angiotensin II prevents hypoxic pulmonary hypertension and vascular changes in rat. Am J Physiol 254: H500-H508, 1988.

SANTOS RAS, FERREIRA AJ, VERANO-BRAGA T, BADER M: Angiotensin-converting enzyme 2, angiotensin(1-7) and Mas: new players of the renin-angiotensin system. J Endocrinol 216: R1-R17, 2013.

SANTOS SHS, GIANI JF, BURGHI V, MIQUET JG, QADRI F, BRAGA JF, TODIRAS M, KONTNIK K, ALENINA N, DOMINICI FP, SANTOS RAS, BADER M: Oral administration of angiotensin-(1-7) ameliorates type 2 diabetes in rats. $J$ Mol Med 92: 255-265, 2014.

SCHERRER U, ALLEMANN Y, REXHAJ E, RIMOLDI SF, SARTORI C: Mechanisms and drug therapy of pulmonary hypertension at high altitude. High Alt Med Biol 14: 126-133, 2013.

SHENOY V, QI Y, KATOVICH MJ, RAIZADA MK: ACE2, a promising therapeutic target for pulmonary hypertension. Curr Opin Pharmacol 11: 150-155, 2011.

SHIMODA LA, LAURIE SS: Vascular remodeling in pulmonary hypertension. J Mol Med 91: 297-309, 2013.

SUGGETT AJ, MOHAMMED FH, BARER GR: Angiotensin, hypoxia, verapamil and pulmonary vessels. Clin Exp Pharmacol Physiol 7: 263-274, 1980.

SYLVESTER JT, SHIMODA LA, AARONSON PI, WARD JPT: Hypoxic pulmonary vasoconstriction. Physiol Rev 92: 367-520, 2012.

VAŇOURKOVÁ Z, KRAMER HJ, HUSKOVÁ Z, VANĚČKOVÁ I, OPOČENSKÝ M, ČERTÍKOVÁ CHÁBOVÁ V, TESAŘ V, ŠKAROUPKOVÁ P, THUMOVÁ M, DOHNALOVÁ M, MULLINS JJ, ČERVENKA L: $\mathrm{AT}_{1}$ receptor blockade is superior to conventional triple therapy in protecting against end-organ damage Cyp1a1-Ren-2 transgenic rats with inducible hypertension. J Hypertens 24: 2465-2472, 2006. 
VARCABOVÁ Š, HUSKOVÁ Z, KRAMER HJ, HWANG HS, HAMMOCK BD, IMIG JD, KITADA K, ČERVENKA L: Antihypertensive action of soluble epoxide hydrolase inhibition in Ren-2 transgenic rats is mediated by suppression of the intrarenal renin-angiotensin system. Clin Exp Pharmacol Physiol 40: 273-281, 2013.

WANG Z, CHESLER NC: Pulmonary vascular mechanics: important contributors to the increased right ventricular afterload of pulmonary hypertension. Exp Physiol 98: 1267-1273, 2013.

WARD JT, MCMURTRY IF: Mechanisms of hypoxic pulmonary vasoconstriction and their roles in pulmonary hypertension: new findings for an old problem. Curr Opin Pharmacol 9: 287-296, 2009.

WHITTAKER P, KLONER RA, BOUGHNER DR, PICKERING JG: Quantitative assessment of myocardial collagen with Picrosirius red staining and circularly polarized light. Basic Res Cardiol 89: 397-410, 1994.

XU P, SRIRAMULA S, LAZARTIGUES E: ACE2/ANG-(1-7)/Mas pathway in the brain: the axis of good. Am $J$ Physiol 300: R804-R817, 2011.

ZHAO L, AL-TUBULY R, SEBHKI A, NUNEZ DJR, WILKINS MR: Angiotensin II receptor expression and inhibition in the chronically hypoxic rat lung. Br J Pharmacol 119: 1217-1222, 1996. 